\title{
TWO CASES OF TRAUMATIC KERATITIS IN THE NEW BORN*
}

\author{
BY \\ W. Gordon M. Byers, M.D. \\ MONTREAL, CANADA
}

THE two following cases of traumatic keratitis in the new born are of special interest because of the findings in the corneae with the slit-lamp. The pathological changes underlying this disorder have been well understond since the classic article of Thomson and Buchanan ${ }^{(1)}$, to whom we are also indebted for our first general description of the clinical picture; but up to the present time apparently no one has had the opportunity of studying these changes with the Gullstrand apparatus.

Case 1.-Mrs. . . . aged 30 years, a patient in the University Maternity Hospital under I)r. J. W. Duncan, was seized with labour pains at 6 p.m. on June 2, 1918. The following day, because of inefficient uterine contractions and irregularity of the foetal heart beats, the forceps was applied (mid-forceps case), and the child was delivered at 4.10 p.m. Great difficulty was encountered in this case owing to the fact that the head presented face to pubes. The pelvic measurements were normal.

The child was of normal size, and weighed eight pounds. It was slightly asphyxiated following delivery, but was readily resuscitated. There was partial paralysis of the seventh nerve on the left side.

I saw the baby on the afternoon of June 4, and noted the following conditions in the left eye: Marked swelling and tumefaction of both lids closing the palpebral fissure; very slight proptosis, and slight chemosis; vertical, and slightly oval band of interstitial infiltration or oedema of the cornea taking in the middle half of this structure for practically the whole of its diameter; corneal epithelium everywhere intact; anterior chamber and iris, hidden beneath the cloudiness, are plainly seen on both sides of the opacity, and appear quite normal. The right eye is unaffected.

During the next twenty-four hours the central haziness extended to practically the whole of the cornea; but, following this, subsidence took place. The paresis of the seventh nerve disappeared within a week of birth.

This spring, that is, after a lapse of six years, I again had the opportunity of examining this patient. She is now a sturdy girl with no suggestion of scarring about the face. The head is tipped

* Read before the American Ophthalmological Society, Hot Springs, Va., June, 1924. 
noticeably to the right and down, and there is a convergent strabismus (markedly spastic) of the left eye. The excursion of the globe, however, is not impaired.

The left eyeball is of the same size as the right, and everywhere of normal appearance, except for the changes in the cornea. In this structure, by ordinary focal illumination (the opacity is not discernible with the naked eye), one sees a faint linear scar running across its entire breadth from eleven to five o'clock. The cicatrix appears uniformly nebulous-has no denser central streak-and measures about $2 \mathrm{~mm}$. in breadth, except over the pupillary area where it is slightly broader and oval in form. The borders, one would say, are rather sharply defined.

With the slit-lamp (oc.2 obj. $\left.\mathrm{a}^{2}\right)$; by diffuse illumination one sees the scar with great clearness; but though magnified, it is of the same form as with ordinary focal illumination. By retroillumination, on the other hand, the cicatrix resolves itself into a cirrus-like opacity, denser in the centre, but fraying finely at the edges, especially on the temporal side. By direct lateral illumination, one sees no thickening of the cornea in the area involved; but one gets a snowy reflection from the deepest layers, and with a narrow bundle one can observe a stratum of greater density immediately at or on Descemet's membrane. There is, in fact, a thin layer of scar-tissue at the posterior surface of the cornea preventing examination in the reflecting zone. Pigment deposits are not discernible.

Pupil, $4 \mathrm{~mm}$. (same as right), regular and active; fundus normal; V. $=1 / 60$ only; field of vision full. Retinoscopy shows an astigmatism as follows : $-5.0 \mathrm{D}$. cyl. $170^{\circ}$; but no improvement in sight can be got with glasses.

Case 2.-Mrs. . . . aged 28 years, was admitted to the Hebrew Maternity Hospital on January 9, 1924. Pelvic measurements; inter-spinous $23 \frac{1}{2} \mathrm{~cm}$.; inter-cristal $25 \frac{1}{2} \mathrm{~cm}$.; external-conjugate $19 \mathrm{~cm}$. After twenty hours of labour, irregularity of the foetal heart developing, the child was delivered as a mid-forceps case at 11.40 p.m. At birth the child was greatly cyanosed and deeply . asphyxiated.

The following afternoon (January 10) the case was seen by Dr. Rosenbaum who made the following notes: Marked ecchymosis of the left side of the face, lids, and forehead; general haziness of the left cornea, but no loss of epithelium, and no circum-corneal congestion ; anterior chamber, of normal depth, shows a hyphaema $3-4 \mathrm{~mm}$. in height; pupil slightly smaller than that of the right eye.

Three days later (January 13) the cornea was decidedly clearer, except for the pupillary area, which showed indefinite clouding. 
The pupil had regained its normal width, and the blood in the chamber was also much less.

On January 23, 1924, Dr. Rosenbaum was kind enough to have the parents bring the case to see me at the Royal Victoria Hospital. All signs of swelling and ecchymosis had disappeared, as well as the hyphaema, and the eye was free from congestion. By focal illumination one saw a typical, but faint, linear opacity, about $4 \mathrm{~mm}$. in breadth, running, across the whole surface of the cornea, from 12.30 to 6.30 o'clock.

It seemed an absurd thing to attempt, but my colleagues were able to hold the sleepy baby at the slit-lamp, and to draw the lids apart so that I was able to see quite distinctly, and a number of times, a rupture of Descemet's membrane by retro-illumination.

On May 1, 1924 (almost four months after birth), I was enabled through the courtesy of Dr. Rosenbaum to see the baby for a second time, and to make the following fuller notes : Left eye : no congestion; pupil regular, active, and of the same size as the right ; no changes in the iris, which is of a slaty colour; extremely faint, slightly oval scar, which occupies the middle third of the cornea over the pupillary area, and runs from 12.30 to 6.30 o'clock. On close inspection the opacity resolves itself into a central band with a long, relatively clear streak in its middle, and three other fine, wavy lines that stand out from the general haziness-one to the inner side, and two to the outer side, of the central band. The opacity to-day is much less pronounced than at the time of our first examination. The fundus is normal.

With the slit-lamp (oc. 2 , obj. $\mathrm{a}^{2}$ ), observations by direct lateral illumination are impossible; but by retro-illumination one again clearly sees the rupture in Descemet's membrane. To-day it shows a very slight double curve like the letter "S." It lies behind the centre of the scar and has the same general line of direction. Its borders are more glistening, and one gets the impression of rounded rather than square edges.

\section{Comment}

Thomson and Buchanan (l.c.) recognized three varieties of change in the cornea following lesions of this structure occurring during labour: (1) a diffuse opacity which is temporary; (2) a diffuse opacity indeterminate in position which is permanent; (3) an opacity which takes a linear form and is permanent.

The cases in the third class, under which the two just reported fall, were shown microscopically by these writers to be due to rupture of the posterior elastic lamina in association at times with rupture of the deep lamellae of the substantia propria; and they 
held that a permanent scar remained in either case as a result of the subsequent formation of cicatricial tissue.

The findings with the slit-lamp of the rupture of Descemet's membrane and of the cicatricial tissue in my second case and in my first case respectively form interesting confirmation of the connection between those changes and the corneal opacity.

The rapid clarification of the cornea in the baby makes it probable, however, that complete disappearance of the nebula will take place at an early date. This outcome would be really more in accord with our clinical experience of simple wounds of the posterior elastic lamina. The point has a bearing upon prognosis.

In my first case, the fact that the opacity, apparently a compact band by ordinary illumination, resolved itself by retro-illumination into a much more widespread and quite irregular scarring, shows as one would expect that we cannot draw hard and fast lines between the cases in Class 1 and those in Class 2 of the Thomson and Buchanan classification.

In one of Thomson and Buchanan's cases, microscopical examination showed masses of pigment granules in the coagulated lymph upon the exposed corneal surface, and between the coils of a ruptured Descemet's membrane. In my second case, where the conditions were favourable, I could not discern pigment. But it has occurred to me that we may have in these birth injuries an explanation of some of the obscure cases of congenital spindleshaped pigmentation of the cornea so ably described by Dr. Holloway ${ }^{(2)}$ before this Society in 1910 .

In the absence of ophthalmoscopic changes, the great reduction of central vision in my first patient must be attributed apparently to an amblyopia from disuse.

Illustrations of the linear scars in traumatic keratitis of the new born having been so well done by Thomson ${ }^{(3)}$ and by James ${ }^{(4)}$, there seemed to one to be no necessity for a further attempt in this direction.

\section{Postscript}

Since reading the foregoing paper at the meeting of the American Ophthalmological Society, June, 1924, I have had the opportunity of seeing a third case of the kind described through the kindness of my colleague, Dr. Fred Tooke.

The patient was a girl, aged six years. Forceps had been used at her birth. Following delivery the eyelids of the right side were greatly swollen and ecchymosed, and the eye could not be opened for a few days. There was an abrasion of the skin near the outer canthus, and another of the right side of the nose, about one- 
half inch below the canthal ligament, where a bony depression can still be felt. One would infer from the statement of the mother in regard to the facial abrasions noticed in this patient immediately after birth that, while the lateral edges of the blade impinged above the points mentioned, the inner edge of the extremity of the blade exerted pressure upon the anterior surface of the cornea, causing rupture.

By diffuse illumination one saw a faint opacity of the cornea, roughly triangular in shape, which occupied the middle two-thirds of the pupillary area. The apex of the scar pointed to eleven o'clock. Its margins appeared sharply defined.

The origin and precise limits of the scar were, however, only revealed by retro-illumination by the slit-lamp. In this lighting one could see with great distinctness, and follow, a characteristic rupture of Descemet's membrane. The fine brilliant line demarcated without interruption an area, spindle-shaped with curved ends, that extended from the extreme periphery of the cornea at five o'clock to almost the extreme periphery at eleven o'clock.

By direct lateral illumination one could see that the opacity was mainly due to a thin layer of scar tissue in the deepest layer of the cornea, though minute opacities were distinguishable like flocculi in the overlying substantia propria. The dense central scar faded gradually toward the periphery.

The affected eye showed a myopia of approximately 15.0D. Central vision, however, was only $3 / 60$ with correction. The other eye was normal with vision $6 / 6$.

\section{REFERENCES}

1. Thomson and Buchanan. - "A clinical and pathological account of some of the injuries occurring to the eye of the child during labour." Trans. Obhthal. Soc. U.K., Vol. XXIII, p. 296, 1903.

2. Holloway, T. B.-"Congenital pigmentation of the cornea." Ann. of Ophthal., Vol. XIX, p. $685,1910$.

3. Thomson, W. Ernest. - "Traumatic keratitis in the new born." Trans. Ophthal. Soc. U.K., Vol. XXII, p. 240, 1902.

4. James, R. R.- " Linear opacity of the cornea following birth injury." Trans. Ophthal. Soc. U.K., Vol. XXIX, p. 12, 1909. 